\title{
Penerapan Manajemen Kinerja Berbasis 3C (Communication, Collaboration and Creativity) Dalam Membentuk Karakter Pada Guru Paud dan TK di Desa Pendem Kecamatan Junrejo Kota Wisata Batu
}

\author{
Marsudi $^{1)}$, R. Iqbal Robbie ${ }^{2)}$ \\ ${ }^{1) 2)}$ Universitas Muhammadiyah Malang, Indonesia \\ Corresponding Author: Marsudi, marsudi@umm.ac.id
}

\begin{abstract}
Abstrak: Perkembangan dunia pendidikan menuntut dinamika yang cepat berkembang dalam berbagai bidang. Guru dituntut mampu mengikuti dan menyesuaikan dengan teknologi yang menciptakan metode pengajaran. Manajemen kinerja mutlak diperlukan oleh para guru PAUD dan TK untuk menghasilkan kualitas, kuantitas dan time lines yang ingin dicapai. Salah satunya melalui proses metode pembelajaran yang mengkolaborasikan teknologi dan siswa untuk cakap dalam menggunakan teknologi tersebut sebagai media belajar dan mampu bekerjasama dengan siswa lain baik secara online maupun offline. Peran guru lebih sebagai fasilitator dalam proses pembelajaran. Berdasarkan hasil pengabdian yang sudah dilakukan, hasilnya adalah pelatihan berjalan dengan baik meski terkendala pandemi, dan peningkatan kreativitas guru dalam menciptakan metode ajar berbasis pendidikan moral.
\end{abstract}

Kata Kunci: manajemen kinerja, pendidikan karakter, guru.

Abstract: The development of the world of education requires dynamics that are rapidly developing in various fields. Teachers are required to be able to follow and adapt to technology that creates teaching methods. Performance management is absolutely necessary for PAUD and kindergarten teachers to produce the quality, quantity and time lines to be achieved. One of them is through the process of learning methods that collaborate technology and students to be proficient in using this technology as a learning medium and able to collaborate with other students both online and offline. The teacher's role is more as a facilitator in the learning process. Based on the results of the dedication that has been done, the results are: training is running well despite the pandemic, and increased teacher creativity in creating teaching methods based on moral education.

Keywords: performance management, character education, teacher.

\section{Pendahuluan}

Kota Wisata Batu semakin dikenal sebagai tempat wisata populer di seluruh pelososk negeri, dengan wisata alam dan wisata perkotaan yang digemari para pihak. Salah satu kecamatan adalah Kecamatan Junrejo yang ada di Kota Batu mempunyai 7 desa antara lain Desa Beji, Desa Dadaprejo, Desa Junrejo, Desa Mojorejo, Desa Pendem, Desa Tlekung dan Desa Torongrejo. Kecamatan Junrejo juga dekat dengan perguruan tinggi yaitu Universitas Muhammadiyah Malang dan Universitas Islam Negeri Maulana Malik Ibrahim. Berdasarkan penjelasan tersebut menunjukkan bahwa dasar masyarakat Kecamatan Junrejo memiliki banyak sekali peluang pada pariwisata sesuai slogan Kota Batu yaitu Kota Wisata Batu.

Untuk menunjang pembangunan Kota Batu maka muncullah keinginan aparat Desa Pendem untuk membuat konsep perencanaan pembangunan yang selaras dengan jargon Kota

Submitted: 14.09.2020, Revised: 09.02.2021, Accepted: 05.04.2021 
Wisata Batu, slogan Desa Pendem yaitu "Kota Berjaya Desa Berdaya", hal ini diterjemahkan dari visi Kepala Desa dan dilaksanakan melalui RPJM Desa tahun 2019 dengan pendampingan dari Tim Pengabdian kami. Salah satu programnya adalah pembangunan fisik dan pembangunan SDM masyarakat. Sebagai kelanjutan dari pendampingan pengabdian tersebut, pihak desa menginginkan peningkatan pemahaman dan potensi masyarakat Desa Pendem melalui penguatan karakter pada anak usia dini. Karena awal pembangunan manusia yang berkualitas dilaksanakan di pendidikan usia dini, tetapi tenaga pengajar harus dibekali dengan kompetensi yang mumpuni karena guru masih banyak yang belum mempunyai kemampuan dalam memberikan pengajaran sesuai dengan perkembangan digital tersebut.

Mitra pengabdian dalam program ini sudah terpetakan dalam rancangan pengabdian yakni guru PAUD dan TK Desa Pendem karena pihak desa akan memetakan berbagai macam potensi yang dimiliki seperti bagaimana kemajuan yang dicapai masyarakat tersebut. Tenaga pendidik dituntut mempunyai keahlian khusus sebelum mentranformasikan pada anak didiknya. Sehingga mereka diharapkan mampu untuk berkompetisi di era revolusi industri 4.0. Di lokasi mitra sendiri, para guru PAUD dan TK di desa pendem kecamatan junrejo dalam hal media ajar untuk membentuk karakter dan moralitas masih belum banyak dilakukan. Sasaran sekolah usia awal, sebetulnya mitra pengabdian mempunyai potensi untuk maju. Berdasarkan pengamatan awal dan mendengar pemaparan pihak desa, tim pengusul mempunyai kesimpulan bahwa kinerja dan tingkat kompeten guru di desa pendem kecamatan junrejo kota batu masih perlu ditingkatkan dan diharuskan ada upaya optimal untuk meningkatkan pemahaman karakter moralitas tersebut. Identifikasi permasalahan yang menjadi kendala mitra terangkum dalam analisis situasi dibawah ini, yakni:

1. Kurangnya pelatihan dalam hal kreatifitas dari pendidik sekolah usia dini dan TK di desa pendem kecamatan junrejo.

2. Minimnya motivasi dan bimbingan guru dalam menerapkan pendidikan moral.

Masalah yang dihadapi guru PAUD dan TK Desa Pendem adalah mereka kurang tepat dalam merencanakan dan merumuskan berbagai macam metode pembelajaran padahal hal tersebut yang akan mengarah kepada kinerja mereka. Masalah yang ada ini menjadi pelecut bagi tim untuk melakukan pendampingan penerapan manajemen kinerja berbasis $3 \mathrm{C}$ sebagai sarana untuk meningkatkan program pembangunan masyarakat Desa Pendem Kecamatan Junrejo Kota Batu.

Dari rangkaian situasi yang menjadi masalah bagi guru di desa tersebut, harus ada solusi yang bagus untuk mengatasinya dengan menggali teori dan praktik bagaimana meningkatkan kreaktifitas dan kreasi guru dalam mengarahkan anak didiknya terhadap karakter moralitas ini. Oleh sebab itu, kegiatan yang dilakukan tim pengabdi ini akan memberikan solusi yang dihadapi oleh mitra salah satunya membentuk training dan dilanjutkan pendampingan dalam pertemuan informal seperti diskusi di bawah supervisi Pemerintah Desa Pendem Kecamatan Junrejo Kota Wisata Batu. Adapun pelatihan meliputi:

1. Pemahaman guru terhadap pentingnya merubah mindset pengajaran.

2. Pengenalan dan penggunaan beberapa media pembelajaran mengenai pendidikan karakter terutama pengenalan konsep 3C

\section{Metodologi}

Mitra pengabdian adalah Guru PAUD dan TK yang berada di Desa Pendem Kecamatan Junrejo Kota Batu, program pengabdian terhadap masyarakat dilaksanakan dengan sistem pelatihan dan pendampingan penerapan manajemen kinerja berbasis $3 \mathrm{C}$. Pelatihan dengan cara 
mempraktikan teori dan literatur pentingnya berubah pemikiran untuk mengikuti revolusi industri. Dan pendampingan dilakukan dengan cara memberikan contoh media pembelajaran yang komunikatif, kolaboratif dan penuh kreatifitas. Adapun langkah-langkah yang ditempuh, pertama adalah melakukan pelatihan dan pendampingan guru Desa Junrejo Kecamatan Junrejo Kota Batu saat melakukan pengajaran pada murid di PAUD dan TK guna melihat apa yang dapat ditingkatkan. Kedua, memberikan penerapan pentingnya konsep pembelajaran berbasis 3 C pada para guru.

\section{Metode Pendampingan dan Materi}

Dalam mencapai luaran program dan hasil kegiatan maka dilaksanakan aktifitas yang disesuaikan sesuai kebutuhan. Secara detail pemecahan masalah yang diajukan antara lain :

1. Program Pelatihan

a. Memberikan teori dan praktik pengetahuan terhadap SDM guru PAUD dan TK mengenai pentingnya pembelajaran $3 \mathrm{C}$.

b. Membangun semangat bagi guru PAUD dan TK untuk memberikan langkah yang maju.

2. Program dalam Pendampingan

a. Mendampingi guru Desa Pendem dalam pemahaman pemikiran pembelajaran dan melakukan pengajaran ke murid.

b. Mendampingi dalam proses pemasaran PAUD dan TK.

\section{Hasil dan Pembahasan}

\section{A. Hasil}

Untuk mewujudkan program yang sudah disepakati antara tim pengabdian dengan mitra, disusunlah rancangan kegiatan yang disesuaikan kebutuhan. Pelaksanaan kegiatan perlu dijadwalkan sesuai dengan kegiatan mitra dan waktu kerja para dosen. Selanjutnya penyusunan langkah-langkah kegiatan supaya kegiatan dapat dilaksanakan sesuai dengan waktu dan metode pelaksanaannya.

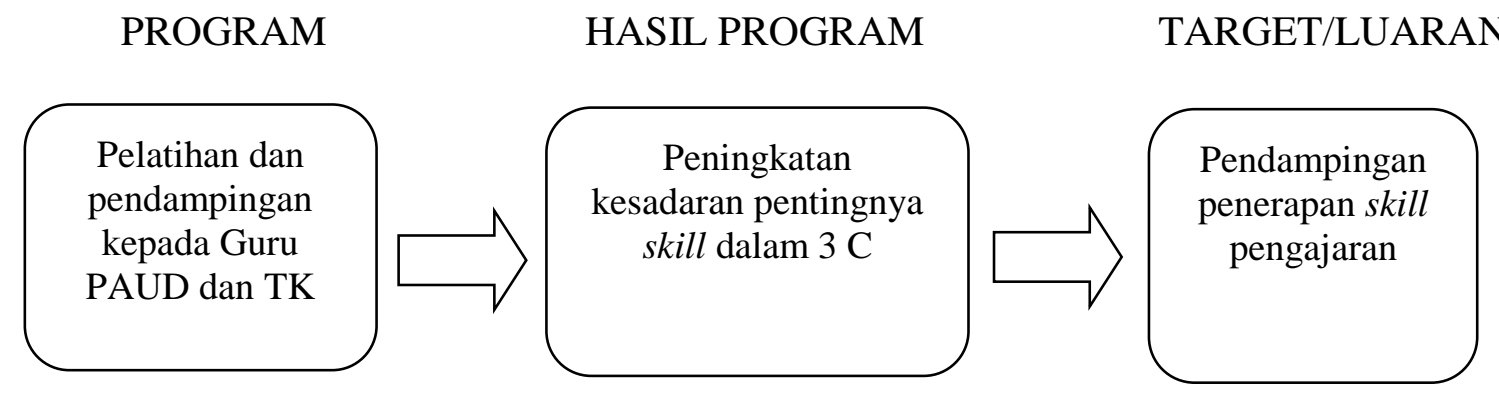

Dengan memperhatikan situasi dan dinamika maka kegiatan disusun seperti gambar diatas. Dalam program tersebut ada dua program yang menjadi prioritas untuk dilaksanakan di desa pendem yakni training guru PAUD dan TK, serta pendampingan dalam penerapan konsep $3 \mathrm{C}$ tersebut kepada murid. Hasil program training tersebut peningkatan pengetahuan dan pemahaman mengenai pentingnya pemahaman guru dalam kreatifitas dalam mengajar. Dalam pelatihan tersebut juga digunakan berbagai media pembelajaran seperti :

1. Media Audio, menggunakan media pembelajaran yang mengandung pesan dalam bentuk auditif (Pendengaran), seperti radio dan kaset. 
2. Media Visual, menggunakan media grafis dan media proyeksi gambar seperti poster, kartun dan komik upin ipin.

3. Media permainan, permainan suatu benda dapat digunakan peserta didik sebagai sarana bermain dalam rangka mengembangkan kreativitas berupa puzzle, ayunan, dan dakon.

Hasil program pendampingan yaitu konsep dan penyusunan potensi soft skill guru untuk disesuaikan dengan program kurikulum pendidikan. Partisipasi mitra dalam kegiatan pengabdian adalah sebagai pelaku pelatihan tersebut, setelah mengikuti pelatihan diharapkan adanya sikap dan perilaku kearah yang lebih baik. Dengan demikian mitra dapat melaksanakan penggalian potensi utamanya dalam pendidikan karakter pada anak usia dini yang lebih terstruktur. Hubungan mitra dan tim pengabdian adalah hubungan konsultatif dan pendampingan, tim pengabdian secara praktis dapat memotivasi guru agar dapat berperan aktif untuk dapat mengatur dan mengelola potensi anak didiknya.

\section{B. Pembahasan}

Langkah-langkah tersebut secara terperinci dapat dilihat pada jadwal pelaksanaan kegiatan berikut:

Tabel 1. Jadwal Pelaksanaan Kegiatan

\begin{tabular}{|c|c|c|c|c|}
\hline Metode & Pelatihan & Pendampingan & Monitoring & Evaluasi \\
\hline Survey & Guru & Guru & $\begin{array}{c}\text { Potensi } \\
\text { Pengajaran }\end{array}$ & $\begin{array}{c}\text { Keakuratan } \\
\text { informasi }\end{array}$ \\
\hline Jumlah & 8 Orang & 8 Orang & 8 Orang & $\begin{array}{l}\text { Kreatifitas } \\
\text { komunikasi }\end{array}$ \\
\hline Tempat & TK Mawar & $\begin{array}{c}\text { TK Permata } \\
\text { Bunda }\end{array}$ & TK & Pengulangan \\
\hline Waktu & Bulan Maret & Bulan Mei & Bulan Agustus & Bulan Agustus \\
\hline Materi & $\begin{array}{c}\text { Pemberian } \\
\text { materi } \\
\text { "merubah mind } \\
\text { set kearah lebih } \\
\text { baik" }\end{array}$ & $\begin{array}{c}\text { Penyusunan } \\
\text { konsep } 3 \mathrm{C} \text { dan } \\
\text { cara } \\
\text { mempresentasika } \\
\text { n }\end{array}$ & $\begin{array}{l}\text { Kunjungan, } \\
\text { diskusi dan } \\
\text { Tanya jawab } \\
\text { di TK }\end{array}$ & $\begin{array}{l}\text { Draft acuan } \\
\text { untuk } \\
\text { pelaksanaan }\end{array}$ \\
\hline Fasilitator & Tim & Tim & Tim & Tim \\
\hline
\end{tabular}

Pendampingan yang sudah dilakukan selama 6 bulan berjalan dengan lancar. Ada perencanaan kegiatan, pelaksanaan dan evaluasi serta kerjasama antara Tim pengabdian dan pihak guru sekolah. Hal yang penting adalah kegiatan tersebut mendapatkan gambaran mengenai potensi dan kemampuan guru yang harus dipetakan menjadi sumber kekuatan dalam melaksanakan pendidikan. Dokumentasi dan berita acara harus ada di setiap kegiatan. Pelatihan yang dilakukan oleh Tim Pengabdian FEB UMM sudah dilaksanakan dengan baik, tetapi perlu dilakukan evaluasi lanjutan seperti cross check keadaan riil di masyarakat khususnya anak didik untuk mendapatkan realitas dalam respon dan kesulitan anak didik dalam menerima pengajaran sehingga penyusunan dokumen akan menjadi manfaat bagi murid. 
Pendampingan yang dilakukan secara intensif dan komunikatif baik secara langsung atau melalui kunjungan akan menjadi sangat efektif, rutinitas pertemuan selanjutnya dengan pihak Pemerintah Desa sebagai mediator untuk memonitor bagaimana efektifitas dan manfaat yang dirasakan oleh masyarakat sekitar. Pendampingan ini akan menimbulkan semangat bagi masyarakat dan aparat desa untuk mengawal proses pembangunan SDM khususnya anak usia dini yang memajukan kualitas Desa Pendem Kecamatan Junrejo ini.

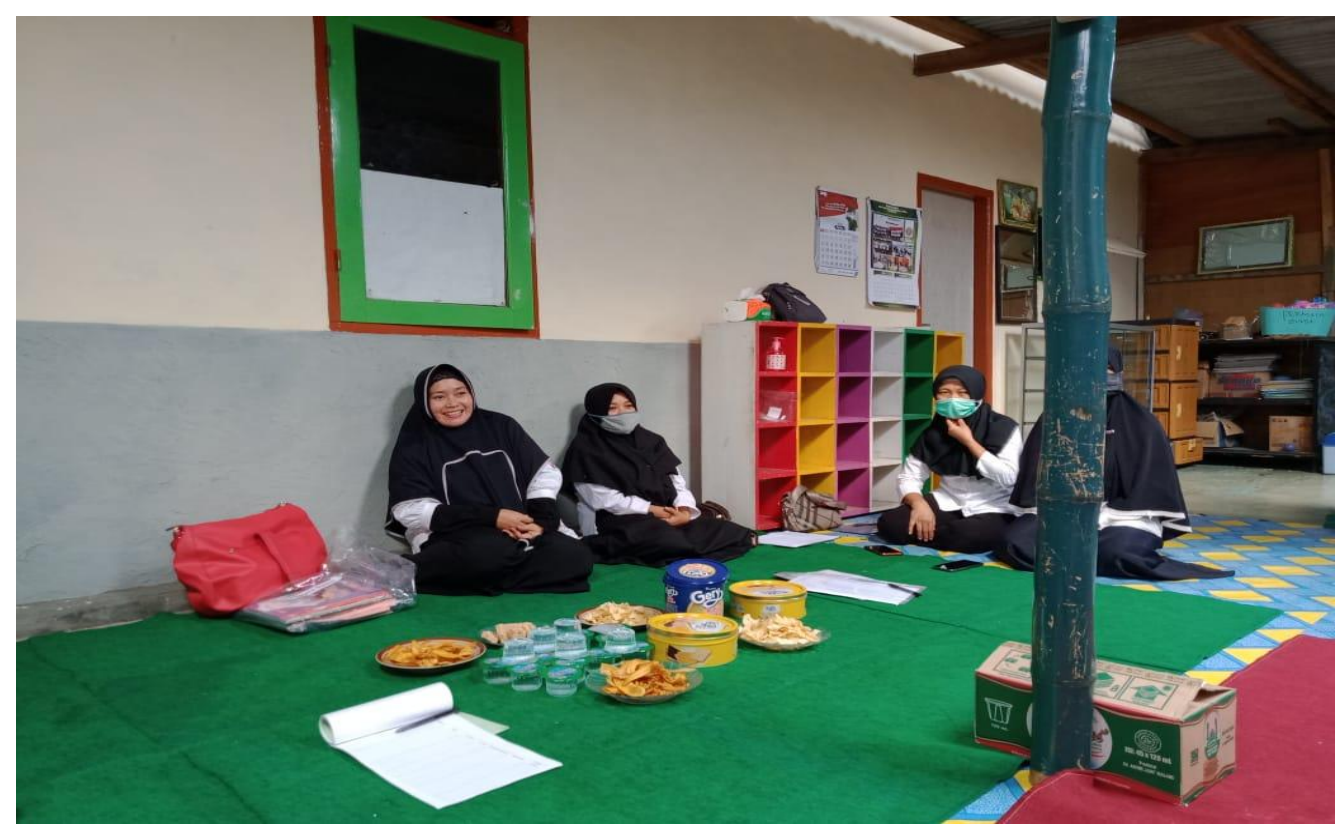

Gambar 1. Pelatihan dan pendampingan di TK Permata Bunda

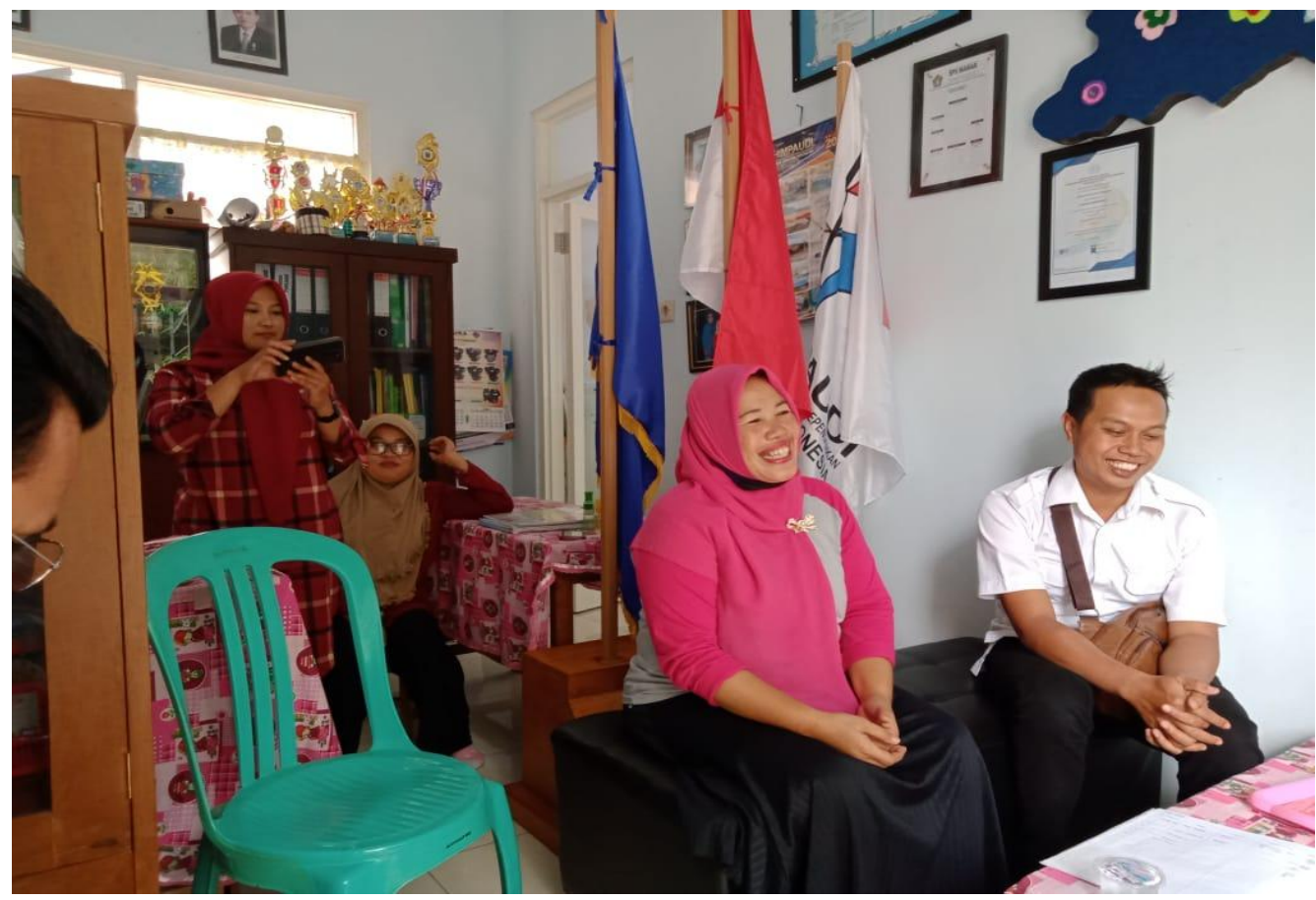

Gambar 2. Pelatihan dan Pendampingan di TK Mawar 


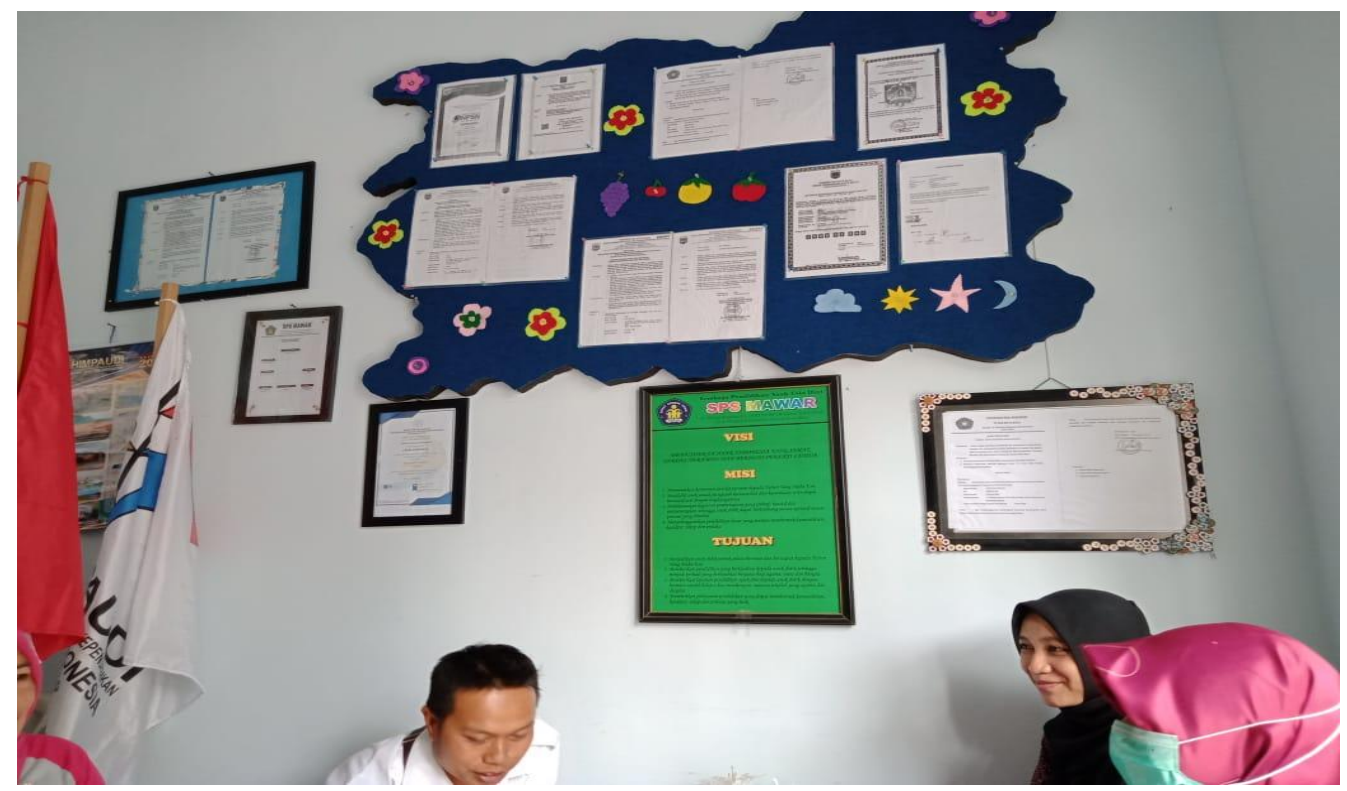

Gambar 3. Penyusunan dan praktik konsep $3 \mathrm{C}$ di TK Mawar

\section{Simpulan}

Pelaksanaan kegiatan pengabdian pada guru PAUD dan TK di Desa Pendem Kecamatan Junrejo Kota Batu telah berjalan dengan baik dan lancar. Secara terperinci kegiatan tersebut dapat disimpulkan sebagai berikut :

1. Pelatihan SDM khususnya guru PAUD dan TK pada pengabdian ini menunjukkan bahwa pelatihan berjalan baik, sehingga warga Desa Pendem Kecamatan Junrejo Kota Batu mempunyai harapan yang tinggi kepada guru untuk menanamkan karakter moralitas bagi anak-anak.

2. Pendampingan pada pengabdian ini telah terlaksana pada saat pengajaran ke anak-anak dengan turun langsung ke rumah masing-masing karena pandemi, sehingga guru yang datang ke rumah murid, ini menunjukkan bahwa warga Desa Pendem Kecamatan Junrejo Kota Batu masyarakat mulai lebih mengerti tentang pendidikan dan pengajaran yang kreatif untuk menyenangkan anak didik.

\section{Ucapan Terima Kasih}

Ucapan terima kasih kepada Universitas Muhammadiyah Malang sebagai institusi kami yang selalu mendukung program pengabdian masyarakat ini, Prodi Manajemen yang memberikan pengarahan dalam program pengabdian masyarakat ini serta Pemerintah Desa dan TK dan PAUD di wilayah Desa Pendem Kecamatan Junrejo Kota Batu atas terjalinnya mitra pengabdian tersebut.

\section{Daftar Pustaka}

Adawiyah, W. R. (2011). Faktor Penghambat Pertumbuhan Usaha Mikro Kecil Menengah (UMKM): Studi di Kabupaten Banyumas (Artikel web).

Basrowi. 2006. Prosedur Penelitian Tindakan Kelas. Kediri: Jenggala Pustaka Utama. 
Endang R Winarti. 2005. Usulan Penelitian Tindakan Kelas: Penerapan Pembelajaran Kooperatif dengan Memanfaatkan Media Kartu dan Poster dalam Upaya Meningkatkan Kemampuan Siswa Menyelesaikan Soal Cerita Matematika di SD Sekaran 01 Semarang. Semarang: Unnes.

Marquardt, M. J. (2002), Building the Learning Organization, Palo Alto, CA: Davies-Black

Mulyono, Sugeng dan Kresnaini, Enlik. (2015). Memetakan Perubahan Organisasi dalam Desain Learning Organization pada Usaha Kecil Menengah di Kota Malang. Jurnal Ekonomi dan Bisnis, 18(1): 101-118

Rivai, Veithzal. (2004). Manajemen sumber daya manusia untuk perusahaan, Cetakan Pertama. Jakarta, PT. Raja Grafindo Persada.

Samir, Alfin dan Larso, Dwi. (2011). Identifikasi Faktor-Faktor yang Mempengaruhi Kinerja UKM Catering di Kota Bandung. Jurnal Manajemen Teknologi. 10 (2).

Soleh, Soemirat. (2008). Dasar-Dasar Public Relation. Bandung: PT. Remaja Rosadakarya.

Thoha, Miftah. (2010). Kepimpinan Dalam Manajemen. Jakarta: Rajawali Press.

Tinneke, M. Tumbel., Liando, Daud., Rumawas, Wehelmina. (2015). Pengaruh Kepimpinan dan Learning Organization Terhadap Kepuasan Kerja Karyawan. Jurnal LPPM Bidang EkoSosBudKum. 2(2):24-35. 